\title{
Construir, habitar e identificar-se quilombola: Uma perspectiva interdisciplinar sob o arrimo jurídico
}

\author{
Build, inhabit and identifying itself quilombola: An interdisciplinary perspective under the legal \\ framework \\ Construir, habitar y identificarse quilombola: Una perspectiva interdisciplinar en el marco legal
}

Recebido: 07/06/2021 | Revisado: 15/06/2021 | Aceito: 17/06/2021 | Publicado: 02/07/2021

Felipe Ibiapina

ORCID: https://orcid.org/0000-0003-3087-6428 Universidade Federal de Pernambuco, Brasil E-mail: ibiapinafelipe@gmail.com

Samuel Rodrigues de Miranda Neto ORCID: https://orcid.org/0000-0003-3977-0187 Universidade de Brasília, Brasil E-mail: samuel_nt@yahoo.com.br

Elaine Ferreira do Nascimento ORCID: https://orcid.org/0000-0002-1632-9148 Fundação Oswaldo Cruz, Brasil E-mail: negraelaine@gmail.com

Liana Maria Ibiapina do Monte ORCID: https://orcid.org/0000-0002-8339-8477 Fundação Oswaldo Cruz, Brasil E-mail: lianaibiapina@yahoo.com.br

Lia Pereira Sabino

ORCID: https://orcid.org/0000-0002-3354-3090

Universidade Federal de Pernambuco, Brasil E-mail: lia_sabino@hotmail.com

\begin{abstract}
Resumo
O ensaio tem como proposta refletir acerca da importância da moradia digna para as comunidades quilombolas, levando-se em consideração as ancestralidades que compõe suas memórias, histórias, culturas, hábitos, costumes, fazeres como uma dimensão fundamental de suas identidades. Para tal, o simbolismo da casa e seu papel na construção subjetiva dos sujeitos que nela habitam fazem parte desse patrimônio e de suas essências. Interseccionando com a temática patrimonial, elege-se como objeto empírico a arquitetura tradicional dos quilombolas da Volta do Campo Grande, comunidade situada na cidade de Campinas do Piauí. Apresenta-se como problema de pesquisa, o questionamento: Quais os elementos materiais e imateriais implicados no processo de identificação dos quilombolas da Volta do Campo Grande com suas habitações? Compõem os procedimentos metodológicos, estudos bibliográficos e documentais, observação direta, entrevistas e fotografia. Para alguns quilombolas da comunidade estudada, a pedra, dentre outras funções - estruturais e estéticas -, exerce o papel de invólucro simbólico da memória. Desta forma, a casa que pode ser considerada o espaço da alma é também o meio pelo qual os sujeitos podem se reconhecer.
\end{abstract}

Palavras-chave: Arquitetura; Casa; Quilombo; Identidade; Pedra.

\begin{abstract}
The essay proposes to reflect on the importance of decent home for quilombola communities, taking into account the ancestors that make up their memories, histories, cultures, habits, customs and actions as a fundamental dimension of their identities. To this end, the symbolism of the house and its role in the specific construction of the individuals who inhabit it are part of this heritage and its essences. Intersecting with a heritage theme, the traditional architecture of the quilombolas in Volta do Campo Grande, a community located in the city of Campinas do Piauí, is chosen as an empirical object. The following question is presented as a research problem: What are the material and immaterial elements involved in the process of identifying quilombolas in Volta do Campo Grande with their homes? It comprises methodological procedures, bibliographic and documentary studies, direct observation, identification and photography. For some quilombolas in the studied community, a stone, among other functions - resource and aesthetic -, plays the role of symbolic covering of memory. In this way, the home that can be considered the space of the soul is also the means by which they can be recognized.
\end{abstract}

Keywords: Architecture; Home; Quilombo; Identity; Stone. 


\begin{abstract}
Resumen
El ensayo propone reflexionar sobre la importancia de la vivienda digna para las comunidades quilombolas, teniendo en cuenta a los antepasados que conforman sus memorias, historias, culturas, hábitos, costumbres y acciones como dimensión fundamental de sus identidades. Para esto, el simbolismo de la casa y su papel en la construcción específica de los sujetos que la habitan forman parte de este patrimonio y sus esencias. En intersección con un tema patrimonial, se elige como objeto empírico la arquitectura tradicional de los quilombolas en Volta do Campo Grande, una comunidad ubicada en la ciudad de Campinas do Piauí. La siguiente pregunta se presenta como problema de investigación: ¿Cuáles son los elementos materiales e inmateriales involucrados en el proceso de identificación de quilombolas en Volta do Campo Grande con sus viviendas? Comprende procedimientos metodológicos, estudios bibliográficos y documentales, observación directa, identificación y fotografía. Para algunos quilombolas de la comunidad estudiada, una piedra, entre otras funciones, recurso y estética, juega el papel de envoltura simbólica de la memoria. De esta forma, la casa que se puede considerar el espacio del alma es también el medio por el cual pueden ser reconocidos.
\end{abstract}

Palabras clave: Arquitectura; Vivienda; Quilombo; Identidad; Roca.

\title{
1. Introdução
}

Porquanto teses jurídicas versam sobre a autoidentificação quilombola como prerrogativa de reconhecimento perante o Estado de Direito, este ensaio se propõe a refletir sobre a importância da seguridade à moradia digna, em sentido amplo, uma vez que constitui condição sine qua nom para a constituição identitária das comunidades quilombolas.

Um dos grandes desafios no campo da garantia ao direito social da moradia dos quilombolas é a proteção das suas tradições ancestrais, sendo a Casa - o modo de morar, os aspectos intersubjetivos e intrassubjetivos mobilizados pela estética do partido arquitetônico - um dos principais marcadores dos aspectos culturais. No entanto, na contramão de tudo isso, os projetos de habitação popular promovidos pelo próprio Estado têm sido feitos de forma leviana, desconsiderando elementos cruciais para o processo de autoidentificação.

Diante do exposto, este ensaio se propõe a refletir sobre o fenômeno da autoidentificação pelo morar, adotando como eixo referencial a Teoria da Arquitetura. Aderindo à interdisciplinaridade, a discussão busca respaldo em outros campos das ciências sociais aplicadas e humanidades, tal como o Direito, o Serviço Social e Psicanálise.

Pensar a arquitetura como um fenômeno cultural, implica em uma consideração sistêmica dos fatos arquitetônicos, em que elementos de ordem material e imaterial encontram-se articulados. Para subsidiar a reflexão, recorre-se a um fato concreto, elegendo-se um objeto empírico. Trata-se da comunidade quilombola Volta do Campo Grande, localizada na cidade de Campinas do Piauí-PI. Observou-se nesta comunidade tensões na paisagem cultural do quilombo, oriundas da inserção de novas habitações padronizadas, segundo o modelo genérico adotado pelos programas de habitação social do Estado, em contraste com as moradas tradicionais em pedra. O que é posto em evidência não é a mudança em si, mas, a (des)identificação dos quilombolas com a remodelação do espaço (arquitetônico, social e cultural), reverberando em uma ameaça pungente ao apagamento da memória e possível desarticulação do grupo. As políticas públicas voltadas à habitação social devem, portanto, atentar para as particularidades de cada caso concreto, sobretudo, em se tratando de grupos historicamente atacados pelo Estado.

Partindo desta problemática, o ensaio busca aprofundar o entendimento acerca da identidade do morar, vislumbrando uma contribuição para a discussão das políticas públicas voltadas para a identidade e para a habitação social. Põe-se em evidência a função simbólica da casa, tema já explorado na literatura da teoria da arquitetura.

No âmbito das discussões teóricas relativas aos significados subjetivos do morar, propõe-se um diálogo analógico, que possa elucidar a questão referente ao caso concreto suscitado. Quais os elementos materiais e imateriais implicados no processo de identificação dos quilombolas da Volta do Campo Grande com suas habitações? Alguns relatos de moradores da comunidade quilombola sugerem que a pedra, dentre outras funções - estruturais e estéticas -, exerce o papel de invólucro simbólico da memória. 


\section{Metodologia}

O percurso metodológico se desenvolveu em duas vias. O objeto empírico aqui investigado já havia sido trabalhado por Siqueira (2014) em uma pesquisa pregressa e parte das informações que serão explanadas no decorrer deste trabalho foram coletadas durante uma visita de campo realizada no ano de 2013. Na ocasião, a problemática de pesquisa focava nas técnicas construtivas vernaculares utilizadas pelos quilombolas. Para tal, fez-se uso da observação participante e entrevistas abertas com alguns moradores do quilombo. Dentre os achados da investigação, chamou atenção a tensão na paisagem cultural do quilombo em razão da inserção das novas tipologias habitacionais. A avaliação da relação dicotômica entre tradição e contemporaneidade na paisagem da comunidade tradicional pesquisada - a paulatina substituição das casas tradicionais de pedra por novas moradias em alvenaria de tijolo, despersonalizadas - acarretou discussões da ordem do patrimônio cultural, levando a pensar alternativas para conciliar progresso e memória.

Ademais, a pesquisa de Siqueira (2014) identificou que havia um apego das pessoas com relação à moradia tradicional em pedra - expressada na resistência à mudança para as novas casas-padrão em alvenaria de tijolos. Diante do exposto, intenta-se uma nova imersão no objeto, sob uma nova ótica: o olhar interdisciplinar acerca dos processos de identificação dos quilombolas, com destaque para a relação dos sujeitos com suas casas. Este texto adota uma metodologia qualitativa, apoiado em pesquisas documentais e bibliográficas.

A pesquisa qualitativa pode ser definida como um estudo não estatístico, que identifica e analisa em profundidade dados de difícil mensuração de um determinado grupo de indivíduos em relação a um problema específico. Entre eles estão crenças, valores e culturas (Minayo, 2013). O método de análise adotado foi a interpretação de sentidos de Gomes (2014). Para o autor as experiências são elementos fundamentais, nessa perspectiva o mundo cultural é um processo que está em constante movimento sendo afetado e afetando os sujeitos que fazem parte dele.

\section{O Quilombo Volta do Campo Grande: uma Reflexão Jurídica da Identificação Comunitária}

Em breve histórico, a formação do quilombo da Volta do Campo Grande se deu entre os anos de 1885 e 1890 por escravizados fugidos e, posteriormente, por ex-escravizados libertos, que se estabeleceram em parte do território das Fazendas Estaduais (na época, nacionais) Castello e Campo Grande. A extensa dimensão das fazendas, e a topografia acidentada do sítio escolhido para a instalação do quilombo contribuíram para a eficácia do refúgio. O início da ocupação se deu com a instalação de três famílias que constituíram os troncos genealógicos fundamentais da comunidade. O critério familiar foi o principal regulador da implantação das habitações no território - quanto maior o grau de parentesco, maior a proximidade (INCRA, 2006).

O legislador constituinte de 1988 se ocupou da questão quilombola em dois pontos: ao tombar os documentos e sítios detentores das reminiscências históricas do que chama de "antigos quilombos", nos termos do art. 216 , $\S 5^{\circ}$, do texto constitucional, e no art. 68 do Ato das Disposições Constitucionais Transitórias, dispositivo mediante o qual é reconhecida às comunidades quilombolas a propriedade definitiva das terras por elas ocupadas, e imposto o dever estatal de demarcação e emissão dos respectivos títulos.

Em que pese se tratar de uma disciplina pouco sistematizada, e, até mesmo, singela, ela reflete o norte condutor da construção do Estado inaugurado com a Constituição da República de 1988: ampliar os direitos e liberdades, precipuamente daqueles grupos que, historicamente, sofreram aviltamento social, cultural e econômico. Nesse sentido:

A Constituição de 1988 é um marco na história do constitucionalismo brasileiro. Expressão dos mais conflituosos anseios de reforma social, produto de uma demorada luta pela redemocratização do país, o seu texto revela a disposição do legislador constituinte de atender simultaneamente às reivindicações de diferentes grupos de interesse. 
Como costuma acontecer com um texto normativo oriundo de uma discussão marcadamente democrática, pautada por concessões, acordos e exigências de todos os tipos, a norma constitucional de 1988 não prima pelo rigor em sua sistematização. Evento com grande carga simbólica, o momento constituinte representou um acerto de contas. Pairava na consciência de todos que se engajaram naquele processo um dever moral de emancipar os grupos desprivilegiados da história nacional, até então alijados das condições necessárias para uma existência digna. Este sentimento se constitucionalizou (Sundfeld, 2002, p. 06-07).

À vista desse tratamento constitucional, a primeira questão juridicamente assentada foi identificar quem são os quilombolas. Por ocasião da promulgação da Carta Constitucional, o único ato normativo correlato à temática ora discutida, mesmo sem nenhuma remissão expressa à causa quilombola, era a Lei n. 7.668/1988, que instituiu a Fundação Palmares, à qual, consoante seu art. $1^{\circ}$, competiria preservar os "valores culturais, sociais e econômicos decorrentes da influência negra na formação da sociedade brasileira"1. Havia, portanto, um vazio legislativo, que somente foi colmatado em 2001, com a edição do Decreto $n^{\circ} 3.912 / 2001$, limitado, contudo, à disciplina formal da demarcação das terras quilombolas, definidas ali como aquelas nas quais, ao tempo da abolição da escravatura, estivessem localizados os quilombos, e, ainda, as ocupadas por remanescentes dessas comunidades, em 05 de outubro de 1988.

Posteriormente, sobreveio o Decreto $\mathrm{n}^{\circ} 4.887 / 2003$, que, de forma efetiva e inédita, conceituou as comunidades quilombolas como "grupos étnicos-raciais, segundo critérios de auto-atribuição, com trajetória histórica própria, dotados de relações territoriais específicas, com presunção de ancestralidade negra relacionada com a resistência à opressão histórica sofrida". Daí se extrai a opção pelo critério identitário da autodeterminação, o que põe por terra o equivocado, minimizador e recorrente discurso histórico, quando se fala em direito dos quilombolas, segundo o qual essas comunidades seriam apenas indivíduos descendentes de grupos escravizados fugitivos. Pertinente, aqui, a doutrina do Professor Edilson Vitorelli:

A leitura do decreto demonstra que há algum equívoco nessa discussão, que costuma se prolongar por anos: em momento algum o decreto exige a comprovação de que a área ocupada tenha sido, há pelo menos 120 anos atrás tendo em vista a data da abolição da escravatura - um "quilombo" nesse sentido histórico estrito. Se assim fosse, a norma teria afirmado que são quilombolas as comunidades que habitam os locais onde comprovadamente os escravos fugitivos se reuniam. Pelo contrário, o que se observa é que o elemento identitário quilombola se centra eminentemente na autoafirmação. É esse dado, que é interno à comunidade, que será a pedra angular para a definição de um grupo quilombola enquanto tal. Os elementos externos, que apenas complementam a definição, é que vêm roubando a cena das discussões jurídicas. É significativo, nesse sentido, que, quando trata da preservação da história, a Constituição utilize as expressões "antigos quilombos", enquanto, ao tratar da proteção dos quilombolas, utilize o termo "remanescentes das comunidades dos quilombos". As comunidades quilombolas são algo vivo, e não a simples reminiscência dos "antigos quilombos" (Vitorelli, 2017, p. 287).

Dessarte, não cabe, juridicamente, cogitar-se o reconhecimento externo da identidade quilombola, tampouco a fixação da data da abolição da escravidão no Brasil para tal; ao revés, o autorreconhecimento confere tão somente à própria comunidade a prerrogativa de assim definir-se, à luz de seus costumes e modo de vida ${ }^{2}$. Tal conclusão tem amparo, outrossim, na Convenção n ${ }^{\circ} 169$ da Organização Internacional do Trabalho, promulgada pelo Decreto $\mathrm{n}^{\circ}$ 5.051/2004 $^{3}$, diploma que consubstancia, no ordenamento jurídico brasileiro a principal disciplina acerca das comunidades tradicionais: segundo o art. $1^{\circ}$,

\footnotetext{
1 A Medida Provisória $n^{\circ}$ 2.216-37/2001, no entanto, acrescentou o inciso III ao art. $2^{\circ}$ da Lei $n^{\circ} 7.668 / 1998$, a fim de inserir, dentre as atribuições da Fundação Palmares, o papel de identificar os remanescentes das comunidades dos quilombos, reconhecer, identificar e demarcar as terras ocupadas, e, por fim, conferir-lhes a titulação. Mais tarde, com a edição do Decreto $n^{\circ}$ 4.887/2003, consoante estabelecido no seu art. $3^{\circ}$, a demarcação e emissão de títulos passou a competir ao Instituto Nacional para Colonização e Reforma Agrária - INCRA.

${ }^{2}$ Oportuno anotar que nem mesmo o fato de o quilombo não estar localizado em área rural afasta sua qualificação como grupo tradicional. Não obstante em sua grande maioria estejam localizadas nessas regiões, as quais, costumeiramente, são mais agregadoras, há comunidades quilombolas localizadas em âmbito urbano, inclusive em grandes capitais (Vitorelli, 2017, p. 297).

${ }^{3}$ Consoante orientação firmada pelo Supremo Tribunal Federal no emblemático julgamento do Recurso Extraordinário $\mathrm{n}^{\circ}$ 466.343, reconhece-se à Convenção $\mathrm{n}^{\circ} 169$ da OIT, por se tratar de tratado internacional sobre direitos humanos, não recebido pelo ordenamento pátrio nos moldes do art. $5^{\circ}$, $\S 3^{\circ}$, da Constituição da República, o status hierárquico supralegal, ou seja, acima das leis, mas abaixo das normas constitucionais
} 
item 2, dessa norma, tem-se na consciência de identidade o critério fundamental para determinação dos grupos sobre os quais recairá a tutela nela prevista. Vale acrescentar que a Organização Internacional do Trabalho buscou, por meio da mencionada convenção, tutelar de modo especial os direitos humanos titularizados pelos grupos que denominou de "povos indígenas e tribais", os quais “careciam (e carecem) de maior proteção diante da herança colonial de controle proletário" (Gonçalves, Souza, Pereira \& Silva, 2017, p. 425).

Além disso, não é outro o entendimento encontrado na jurisprudência dos Tribunais Superiores brasileiros. Com efeito, há mais de uma década, no julgamento do Recurso Especial n 931.060/RJ, de relatoria do Ministro Benedito Gonçalves - atualmente, o único magistrado negro ocupando uma das 33 vagas da Corte máxima em matéria infraconstitucional no Brasil -, o Superior Tribunal de Justiça encampou, dentre outros fundamentos, o critério da autoatribuição identitária para desprover ações de reintegração de posse ajuizadas pela União contra famílias integrantes de comunidade quilombola localizada na Ilha de Marambaia, no Estado do Rio de Janeiro.

A seu turno, em fevereiro de 2018, o Supremo Tribunal Federal enfrentou a questão no julgamento da Ação Direta de Inconstitucionalidade $n^{\circ} 3.239$, ajuizada em face de vários dispositivos do Decreto $n^{\circ} 4.887 / 2003$. Um dos argumentos levantados na ação ${ }^{4}$ diz, justamente, com a suposta inconstitucionalidade da regra do autorreconhecimento adotada pela norma, porquanto, a partir de tal parâmetro, seria conferido ao próprio grupo interessado o poder de atribuir a si os direitos daí decorrentes.

No precedente, cujo Relator originário foi o Ministro Cezar Peluso, ficando como redatora do acordão a Ministra Rosa Weber, a Corte Constitucional repeliu firmemente tal alegação, com supedâneo no objetivo fundamental de construir uma sociedade livre, justa e solidária, assumido pela República Federativa do Brasil no art. $3^{\circ}$ da Constituição Federal de 1988, além da norma protetiva estampada na já menciona Convenção nº 169 da OIT, como espelham os itens da ementa do julgado colacionados a seguir:

AÇÃO DIRETA DE INCONSTITUCIONALIDADE. DECRETO No 4.887/2003. PROCEDIMENTO PARA IDENTIFICAÇÃO, RECONHECIMENTO, DELIMITAÇÃO, DEMARCAÇÃO E TITULAÇÃO DAS TERRAS OCUPADAS POR REMANESCENTES DAS COMUNIDADES DOS QUILOMBOS. ATO NORMATIVO AUTÔNOMO. ART. 68 DO ADCT. DIREITO FUNDAMENTAL. EFICÁCIA PLENA E IMEDIATA. INVASÃO DA ESFERA RESERVADA A LEI. ART. 84, IV E VI, "A", DA CF. INCONSTITUCIONALIDADE FORMAL. INOCORRÊNCIA. CRITÉRIO DE IDENTIFICAÇÃO. AUTOATRIBUIÇÃO. TERRAS OCUPADAS. DESAPROPRIAÇÃO. ART. $2^{\circ}$, CAPUT E $\S \S 1^{\circ}, 2^{\circ}$ E $3^{\circ}$, E ART. 13, CAPUT E $\S 2^{\circ}$, DO DECRETO N 4.887/2003. INCONSTITUCIONALIDADE MATERIAL. INOCORRÊNCIA. IMPROCEDÊNCIA DA AÇÃO. [...]

6. O compromisso do Constituinte com a construção de uma sociedade livre, justa e solidária e com a redução das desigualdades sociais (art. $3^{\circ}$, I e III, da CF) conduz, no tocante ao reconhecimento da propriedade das terras ocupadas pelos remanescentes das comunidades dos quilombos, à convergência das dimensões da luta pelo reconhecimento expressa no fator de determinação da identidade distintiva de grupo étnico-cultural - e da demanda por justiça socioeconômica, de caráter redistributivo - compreendida no fator de medição e demarcação das terras.

7. Incorporada ao direito interno brasileiro, a Convenção 169 da Organização Internacional do Trabalho - OIT sobre Povos Indígenas e Tribais, consagra a "consciência da própria identidade" como critério para determinar os grupos tradicionais aos quais aplicável, enunciando que Estado algum tem o direito de negar a identidade de um povo que se reconheça como tal. 8. Constitucionalmente legítima, a adoção da autoatribuição como critério de determinação da identidade quilombola, além de consistir em método autorizado pela antropologia contemporânea, cumpre adequadamente a tarefa de trazer à luz os destinatários do art. 68 do ADCT, em absoluto se prestando a inventar novos destinatários ou ampliar indevidamente o universo daqueles a quem a norma é dirigida. O conceito vertido no art. 68 do ADCT não se aparta do fenômeno objetivo nele referido, a alcançar todas as comunidades historicamente vinculadas ao uso linguístico do vocábulo quilombo. Adequação do emprego do termo "quilombo" realizado pela

\footnotetext{
${ }^{4}$ Questionou-se, ainda, em síntese, a falta de arrimo legal do Decreto $n^{\circ} 4.887 / 2003$, bem como a inconstitucionalidade da desapropriação indenizada para a transferência de propriedade das terras ocupadas pelos quilombolas, e da delimitação das terras por indicação das próprias comunidades. Tais alegações foram igualmente repelidas pelo Supremo Tribunal Federal, tendo sido a ação julgada improcedente em sua integralidade.
} 
Administração Pública às balizas linguísticas e hermenêuticas impostas pelo texto-norma do art. 68 do ADCT. Improcedência do pedido de declaração de inconstitucionalidade do art. $2^{\circ}$, $1^{\circ}$, do Decreto 4.887/2003.

[...] Ação direta de inconstitucionalidade julgada improcedente.

Por fim, destacamos o caso "Comunidades Afrodescendentes deslocadas da Bacia do Rio Cacarica (Operação Gênesis) versus Colômbia”, sentenciado pela Corte Interamericana de Direitos Humanos (Corte IDH) em 2013.

Sobre o contexto fático da "Operação Gênesis":

Os fatos ocorreram durante a "Operação Gênesis", que foi uma operação militar realizada na zona do rio Cacarica com o objetivo de capturar membros do movimento de guerrilha Forças Armadas Revolucionárias da Colômbia (FARC). A operação foi realizada em conjunto por forças paramilitares e forças armadas colombianas. Durante a operação, além do deslocamento forçado de milhares de pessoas, sendo a grande maioria comunidades afrodescendentes que viviam no território afetado pela operação, também foram deslocados cerca de 530 agricultores que possuíam terras na região. Durante o deslocamento forçado da população afetada, um dos líderes comunitários, o sr. Marino López Mena, foi executado (Paiva \& Heemann, 2020, p. 244).

Nesse precedente, ao condenar o Estado colombiano em razão da violação dos direitos à vida, integridade pessoal, circulação e residência, e de garantias judiciais dos vitimizados, além de reconhecer, inauguralmente, uma comunidade de ancestralidade africana fora do conceito de comunidade tribal, cuja referência, até então, valia para todos os grupos de etnia distinta da indígena, a Corte IDH assentou o direito de propriedade coletiva das terras ocupadas tradicionalmente por esses povos, cuja participação no processo de retomada foi assegurada.

Observa-se, diante de todo esse cenário, que a tutela normativa e jurisprudencial dos costumes e tradições das comunidades quilombolas lhes garante um verdadeiro direito subjetivo coletivo de autodefinição identitária, o qual serve, ao fim e ao cabo, de instrumento de reparação histórica das gravíssimas violações aos direitos humanos desses grupos, verificadas, infelizmente, até os dias hodiernos.

\section{As Habitações da Volta do Campo Grande}

A tradição construtiva da comunidade da Volta do Campo grande caracteriza-se, sobretudo, pelo uso da pedra não aparelhada e variantes híbridas com a utilização do barro. Observa-se no território quilombola exemplares arquitetônicos executados exclusivamente em pedra, a partir da técnica do canjicado, com a pedra aparente sem nenhum recobrimento e, nos modelos híbridos, associa-se a pedra com a taipa de mão, utilizando esteios verticais de madeira e barro como elemento ligante (Siqueira, 2014).

As variações na técnica tradicional das construções em pedra podem ter sido mobilizadas por alguns fatores, dentre eles, o processo de reconstrução das casas - o costume de se reconstruir a casa herdada dos pais e avós, realocando a habitação no território. Concernente a isso, durante as reformas mais recentes, é provável que o uso misto da pedra com a taipa tenha se apresentado como uma necessidade, seja pelo fato de não se achar tão facilmente pedras que pudessem se encaixar na estrutura das vedações verticais ou pelo fato do conhecimento da técnica construtiva original ter se esvaído no tempo (Siqueira, 2014).

Um segundo ponto diz respeito às frestas, comuns às vedações de pedra, e sua contribuição para a insalubridade do meio, uma vez que se transformam em habitat para o inseto barbeiro, hospedeiro da Doença de Chagas que é causa de muitas mortes entre os moradores da região. Apesar da taipa não garantir uma grande eficiência na proteção da residência contra o barbeiro por estar sujeita a rachaduras, ainda assim, se mostra como uma alternativa na tentativa de aprimorar a vedação dos fechamentos laterais, podendo ser esse um dos motivos do seu uso misto com a pedra (Siqueira, 2014).

Na Figura 1, apresenta-se um exemplar arquitetônico da técnica hibrida da pedra com a taipa. Nesta, são usados esteios verticais de madeira para garantirem maior aderência do barro e armarem a estrutura. Troncos, como o de carnaúba ou 
no formato de forquilha, são adossados à parede e são eles que garantem a sustentação da cobertura que é composta por telha cerâmica disposta em duas águas, com ripas feitas de bambu, caibros e terças com toras de madeira redonda da região. O uso da telha cerâmica é um dado da modernidade, uma vez que no passado, de certo, a coberta era executada com fibras vegetais. O piso em estado bruto é feito de barro batido. As portas e janelas contam com portais que garantem sua estruturação. As divisões internas ficam por conta de meias paredes. Com vista a coibir a presença do hospedeiro da Doença de Chagas, algumas paredes são rebocadas com argila. No caso ilustrado, observa-se que o reboco e a caiação na parede da fachada principal atuam, também, como artifício de diferenciação estética (Siqueira, 2014).

Figura 1: Arquitetura tradicional quilombola na comunidade Volta do Campo Grande.

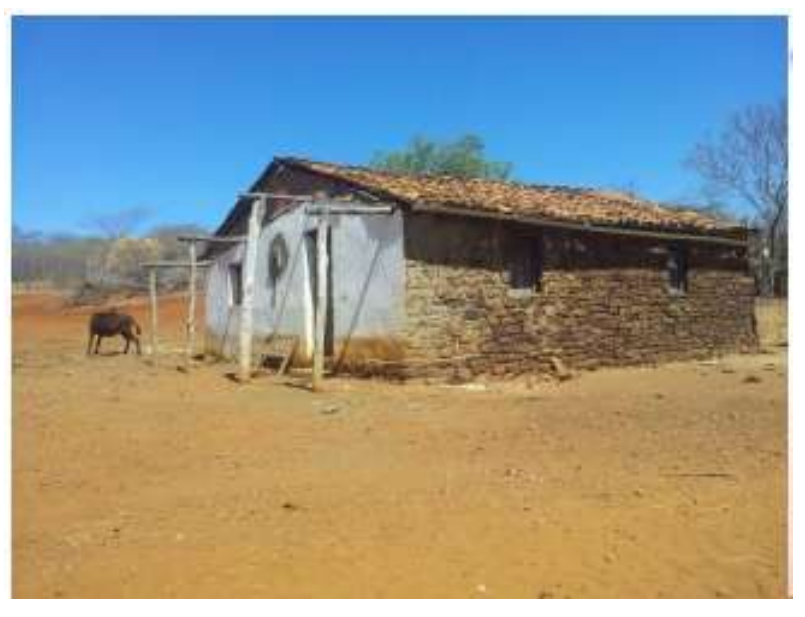

Fonte: Siqueira (2014).

Conforme apontado na introdução, na última década, alguns moradores foram contemplados pelo Governo Federal com casas populares que se enquadram no padrão da habitação de interesse social, construídas com alvenaria de tijolos de furo. Os beneficiados, apesar de terem ganhado uma moradia de "melhor qualidade" - destaca-se a ressalva porque não se coaduna com essa valoração insuflada no senso comum, que representa os ideais tecnocráticos moldados em critérios técnicos e estéticos de base racionalista -, passaram a se dividir entre as duas casas, utilizando a nova como abrigo e a tradicional em pedra como morada, onde passavam o dia. Diante dessa breve descrição acerca do objeto empírico, segue uma reflexão acerca dos significados dicotômicos abrigo/morada referentes ao significante casa e o sentido simbólico da mesma.

\section{A Função Simbólica da Casa}

A distinção entre os significados de abrigo e morada que fazem referência ao significante casa, encontra ancoragem no plano do simbólico. Com efeito, os significados arrolados fazem jus a sentidos distintos: enquanto que o abrigo está mais próximo dos aspectos tangíveis, tal como a proteção contra as intempéries, a morada compreende o invisível, subjacente às necessidades subjetivas dos sujeitos.

Ao tratar da casa, a partir da leitura feita por Rykwert (2009) em "Casa de Adão no Paraíso", Leitão (2007, p.65) acentua que "muito além da materialidade que mais facilmente a caracteriza, a construção da casa humana é, na verdade, um espaço para a alma”. Ou seja, ainda que o significado de abrigo, viés funcionalista relativo à salvaguarda física do corpo, sobrevenha com mais facilidade à mente consciente quando se faz menção à casa, existe um outro significado, ainda mais amplo, que - ousa-se dizer - traduz a ontologia da casa: o de espaço para a alma, para se demorar, para retornar, para se reconhecer. 
A casa que constitui morada humana pode servir de abrigo, mas o contrário nem sempre é verdade. O "abrigar-se" não é uma condição exclusiva da espécie humana e animais também o fazem, tanto que nos primórdios não haviam grandes distinções entre o modo como estes e os hominídeos se abrigavam: as cavidades naturais, cavernas, buracos, etc.

Fazendo uso de uma narrativa alegórica, Vitrúvio (1787) conta que os homens viviam em meio à natureza, dividindo o espaço das selvas, grutas e bosques com as feras. Com o advento da descoberta do fogo, algumas mudanças teriam ocorrido na vida do homem primitivo, tal como a proteção contra o frio e a defesa contra os animais ferozes. Em razão desses condicionantes, deu-se um princípio de agregação que acarretou no desenvolvimento da linguagem e no surgimento das primeiras construções. Em tese, adota-se como pressuposto, que a função abrigo se torna insuficiente, florescendo a noção ampliada de casa, à medida que emerge a linguagem e o humano se insere na ordem do simbólico.

Um sem fim de significados subjetivos podem ser atribuídos à casa. A experiência do morar, ainda que parta da coletividade e do convívio com o Outro, se desenvolve particularmente em cada indivíduo, ensejando que as atribuições de valor e a significação da morada opera de modo diferente para cada um.

Todavia, para o entendimento de uma noção ampla e geral da casa - à guisa de uma reflexão ontológica que, não necessariamente, exclui a noção particular -, recorre-se à teoria da arquitetura, adotando como referência as definições de espaço anteriormente citadas: espaço para a alma, espaço para se demorar, espaço para retornar, espaço para se reconhecer.

De início, elucida-se que o espaço aqui referenciado é, necessariamente, o espaço da arquitetura e, enquanto tal, "se define por um vazio, que o constitui em consequência de uma ação humana compositiva" (Leitão \& Lacerda, 2016, p.809). A partir desse entendimento, é possível fazer a primeira distinção ontológica entre casa (sentido amplo) e abrigo. A casa, ao contrário do abrigo, é uma construção humana, fruto de uma intencionalidade geradora, uma ideia original - arkhé - que se consubstancia na matéria - tékton.

Entre os antigos - utiliza-se como referência as civilizações grega e romana, raiz ancestral da cultura Ocidental - a casa era a morada dos mortais e dos seus ancestrais, representados pelo fogo sagrado. É pressuposto que o culto aos mortos associado ao fogo sagrado influenciou na configuração primeva da casa e, foi por ela influenciado, em uma dinâmica de correspondências recíprocas. Em decorrência da religião doméstica, os antigos gregos e romanos tiveram a necessidade de uma moradia perene. Eles acreditavam que o morar era uma condição inalienável, a qual não cabia finitude. Nas palavras de Coulanges (2002, p.69): "levantavam-se as paredes em redor do altar para o isolar e defender [o fogo sagrado], e podemos afirmar, como os gregos, que a religião ensinou a construir a casa”. Esse laço entre a casa e o sagrado conota a qualidade do espaço arquitetônico enquanto morada da alma. O simbolismo do Lar transcende a existência material, o que pode ser exemplificado a partir da dupla referência ao significante Lar, que tem como significados a casa e o deus - este associado ao fogo sagrado e aos antepassados mortos.

Hodiernamente, ainda que não haja o fogo sagrado, a memória dos antepassados mortos subsiste no lar, seja em relíquias materiais ou na cultura transgeracional que integra os descendentes e a ancestralidade. Portanto, ainda faz sentido pensar na casa como o espaço para a alma, sobretudo se essa alma, mais do que referenciar o morto, disser respeito ao ser vivente, ao mortal que ali habita.

O referido habitar é tratado em sentido amplo que, no olhar de Heidegger (2012), consiste em uma condição dos mortais de demorar-se sobre a terra. Concordando com a posição do filósofo de que só é possível habitar o que se constrói, defende-se que o espaço construído - e a casa pode ser considerada o exemplar fundamental - é parte de todas as experiências vividas pelo humano em sua "demora". Analogamente, diz Coutinho (1977, p.210) que "o espaço interior [arquitetônico] é de si mesmo a ilustração de uma conjuntura filosófica: a de ser presente em alguma parte".

Uma outra interpretação que pode ser dada à casa enquanto espaço para alma e espaço para se demorar, diz respeito à sua função de sucedâneo do útero materno, suscitada por Freud. Acerca desta, diz Leitão (2007, p.66): “o espaço da 
arquitetura se fez por não se poder evitar. [...] porque uma memória, inconscientemente inscrita no psiquismo, guiou o humano em direção às cavidades", em uma tentativa de reconstituir o espaço intrauterino.

Mumford (1989) rememora que no antigo Egito, o hieróglifo (significante) que se relacionava com o significado de mãe, era o mesmo de casa, o que reforça a tese freudiana. O espaço para retornar, aqui atribuído à casa, diz respeito à tentativa (sem êxito) do sujeito aplacar a angústia primordial, através do retorno para a condição de completude que é o estado intrauterino ou, pelo menos, a fase psíquica de indiferenciação mãe-bebê (que vai do nascimento até os primeiros meses de vida). "Repensando a natureza da angústia, Freud descobre, no desamparo primordial do nascimento, a angústia na sua forma originária - a Urangst. Ela se repete nas diversas formas de angústia de separação que nos acompanha do nascimento à morte" (Rocha, 1999, p.339).

Assim, como uma sina perpétua, o sujeito vivencia uma busca pelo caminho "de volta" à completude. A casa enquanto arquitetura, espaço que inclui o humano e espaço para retornar - "[...] permite reviver a ilusão de volta a espaços, tempos e memórias que um dia foram caros ao ser humano, quer individual, quer coletivamente falando" (Leitão, 2007, p.67).

Por fim, apresenta-se a perspectiva de casa como espaço para se reconhecer, fundamentada na analogia casa-espelho, cuja proposta é lançar uma visão ampla sobre o fato arquitetônico, integrando espaço e forma - ponto essencial diante do intento de analisar a arquitetura quilombola em pedra. Refletindo, a partir da teoria lacaniana, Leitão (2011, p.63) defende que "os desenhadores do mundo imprimem as linhas do seu rosto na forma que produzem porque essa é a imagem que trazem impressas em si mesmos como parte da experiência psíquica de estruturação do Eu". Portanto, se existe uma componente de não-intencionalidade integrada ao processo de produção do espaço, tal como a construção da casa, e essa componente reflete aspectos da subjetividade individual ou - em maior escala, de grupo -, é presumível que a arquitetura standartizada não gere empatia, como se observa no caso concreto em estudo.

Os relatos de alguns habitantes da Volta do Campo Grande reforçam os significados simbólicos que foram alçados para definir o sentido amplo de casa. O primeiro ponto diz respeito ao fato de que técnica tradicional das construções em pedra, e suas variações com o barro, foi aprendida com os antepassados. Ou seja, destaca-se o "saber construtivo" como um elo transgeracional, o que por si só, justificaria o "apego à tradição", e o porquê da casa tradicional de pedra gerar identidade nos moradores e as casas padronizadas de tijolos não. Todavia, destaca-se que, para além da técnica que é "lembrada", coexistem memórias difusas, transgeracionais, que se expressam no ato construtivo como as "linhas do rosto".

Outro ponto diz respeito ao costume, presente entre os quilombolas da Volta, de reformar suas habitações utilizando como matéria-prima as pedras reminiscentes de outras construções que lhes foram herdadas de seus pais e avós. Ou seja, constitui uma prática recorrente a demolição de casas antigas e o reaproveitamento dos seus materiais construtivos nas reformas de ampliação ou, até mesmo, na construção de novas casas. A mesma pedra que sustentava a habitação dos antepassados passa a ser utilizada pelos descendentes e, assim, de algum modo, se mantém uma continuidade que extrapola a imaterialidade do "saber fazer técnico" e da memória transgeracional inconsciente, agindo na concretude da matéria, a pedra. Tudo isso faz pensar que a pedra além de portadora das propriedades naturais que lhes são próprias, mostra-se também como um elo entre os antigos habitantes do quilombo e os atuais, seja em sentido literal, quando na ocasião de reconstruções, seja encarnando em si uma parte importante da memória do grupo.

A partir do significado simbólico da casa, algumas hipóteses são levantadas - sem intento resolutivo - a pedra (fundamental), em sua materialidade, traria para o espaço interno da morada a presença do pai morto (da mãe e dos demais ancestrais que partiram), tal como acontecia com o fogo sagrado? A partir daí, seria reforçado o caráter da casa enquanto espaço para a alma e espaço para retornar? A componente tectônica da casa, figurada nas qualidades materiais da pedra criaria uma ambiência de familiaridade, considerando que há gerações "é assim que se mora"? Novamente, isso reforçaria o caráter de espaço para retorno e para se reconhecer? 


\section{Considerações Finais}

Apesar de conclusões não serem possíveis - tampouco houve essa pretensão -, em resposta ao problema de pesquisa levantado, entendeu-se que a identificação dos quilombolas da Volta do Campo Grande e suas habitações: (1) perpassa a materialidade e expressão tectônica da construção em pedra, parte integrante do modelo arquitetônico tradicional; (2) tem conexão com o fato da pedra portar um valor simbólico equivalente à relíquia, fazendo memória aos antepassados, e outros valores simbólicos que se desconhece mas que encontram ancoragem na cultura local; (3) decorre da possibilidade de expressão através da técnica construtiva e da fruição subjetiva.

As intervenções estatais precisam levar em conta a ancestralidade de um povo, uma vez que essa morada de pedra inspira um processo de reparação identitária. As ações do Estado, quase sempre, incorrem em uma (des)identificação dos quilombolas com a remodelação do espaço (arquitetônico, social e cultural), promovendo às vezes um apagamento da memória e possível desarticulação do grupo, cenário que representa clarividente antinomia com o critério de autodefinição, pacificamente consolidado na disciplina normativa e na jurisprudência. Nesse sentido, as políticas públicas voltadas à habitação social devem, portanto, atentar para as particularidades de cada caso concreto, sobretudo, em se tratando de grupos historicamente atacados pelo Estado.

Como sugestão para estudos continuados, propõe-se uma pesquisa-ação, junto à comunidade Volta do Campo Grande, buscando captar as nuances do morar defendidas pelo grupo, bem como, inventariar suas técnicas construtivas, de modo a aplicar esses conhecimentos em projetos arquitetônicos que sirvam de base referencial para as futuras construções do grupo, inclusive, aquelas que integram uma perspectiva ações populares em larga escala.

\section{Referências}

Coulanges, F. (2002). A cidade antiga. Martin Claret.

Coutinho, E. (1977). O espaço da arquitetura. Editora Perspectiva.

Constituição da República Federativa do Brasil de 1988. (1998). https://www.planalto.gov.br/ccivil_03/constituicao/constituicao.htm

Decreto $n$. 3.912, de 10 de setembro de 2001. (2001). Regulamenta as disposições relativas ao processo administrativo para identificação dos remanescentes das comunidades dos quilombos e para o reconhecimento, a delimitação, a demarcação, a titulação e o registro imobiliário das terras por eles ocupadas. https://www2.camara.leg.br/legin/fed/decret/2001/decreto-3912-10-setembro-2001-395404-norma-pe.html

Decreto 4.887, de 20 de novembro de 2003. (2003). Regulamenta o procedimento para identificação, reconhecimento, delimitação, demarcação e titulação das terras ocupadas por remanescentes das comunidades dos quilombos de que trata o art. 68 do Ato das Disposições Constitucionais Transitórias. https://www2.camara.leg.br/legin/fed/decret/2003/decreto-4887-20-novembro-2003-497664-norma-pe.html

Gomes, R. (2014). Análise e interpretação de dados de pesquisa qualitativa. In: Minayo, M.C.S. Pesquisa social: teoria, método e criatividade. Petrópolis: Vozes, p. 79-108.

Gonçalves, E. R., Souza, E. G. de, Pereira, N. M. F. de S. \& Silva, S. V. da (2017). Legislação Internacional Comentada. JusPodium.

Heidegger, M. (2012). Construir, habitar e pensar. In: Heidegger, M. Ensaios e Conferências. (pp. 125-141). Vozes.

INCRA (2006). Relatório Técnico de Identificação e Delimitação do Território da Comunidade Negra Remanescente de Quilombo Volta do Campo Grande. Teresina.

Leitão, L. (2007). Entra na tua casa: anotações sobre arquitetura, espaço e subjetividade. In: Leitão, L. \& Amorim, L. A casa nossa de cada dia. (pp.49-69). Recife: Ed. Universitária da UFPE.

Leitão, L. (2011). Uma relação especular: anotações sobre a dimensão imaginária da arquitetura. RISCO, 13(01), 58-64.

Leitão, L. \& Lacerda, N. (2016). O espaço na geografia e o espaço na arquitetura: reflexões epistemológicas. Caderno das Metrópoles, 18(17), 803-822.

Minayo, M. C. S. (2013). O desafio do conhecimento: pesquisa qualitativa em saúde. (13a ed.), Hucitec.

Mumford, L. (1989). The City in History. Harcourt.

Paiva, C. \& Heemann, T. A. (2020). Jurisprudência Internacional de Direitos Humanos. CEI. 
Research, Society and Development, v. 10, n. 7, e56810716897, 2021

(CC BY 4.0) | ISSN 2525-3409 | DOI: http://dx.doi.org/10.33448/rsd-v10i7.16897

Rocha, Z. (1999). Desamparo e metapsicologia: para situar o conceito de desamparo no contexto da metapsicologia freudiana. Síntese- Revista de Filosofia, 04, 71-80.

Rykwert, J. (1987). El útero y la tumba. AV Monografías (12), 18-21.

Rykwert, J. (2009). A casa de Adão no Paraíso: a ideia da cabana primitiva na história da arquitetura. Perspectiva.

Siqueira, F.I.M.R. (2014). Quilombo de pedra: análise arquitetônica da comunidade quilombola Volta do Campo Grande. Ciências e Saberes: série científica. (4), pp.71-80

Sundfeld, C. A. (2002). O Direito à Terra das Comunidades Quilombolas (Artigo 68 do Ato das Disposições Constitucionais Transitórias). Sociedade Brasileira de Direito Público - sbdp.

Vitorelli, E. (2017). Estatuto da Igualdade Racial e Comunidades Quilombolas: Lei 12.288/2010, Decreto 4.447/2003. JusPodium.

Vitrúvio. (1787). Los Dies Libros de Architectura. Imprenta Real. 